\section{(2) OPEN ACCESS}

\title{
EMA's mishandling of an investigation into suspected serious neurological harms of HPV vaccines
}

\section{Peter C Gøtzsche $(1),{ }^{1}$ Karsten Juhl Jørgensen ${ }^{2}$}

\subsection{6/bmjebm-2020-111470}

${ }^{1}$ Institute for Scientific Freedom, Hørsholm, Denmark ${ }^{2}$ Nordic Cochrane Centre, Copenhagen, Denmark

Correspondence to: Dr Peter C Gøtzsche, Institute for Scientific Freedom, Hørsholm 2970, Denmark; pcg@scientificfreedom.dk

\section{Check for updates}

(-) Author(s) (or their employer(s)) 2021. Re-use permitted under CC BY-NC. No commercial re-use. See rights and permissions. Published by BMJ.

\begin{tabular}{|l|}
\hline To cite: Gøtzsche PC, \\
Jørgensen KJ. BMJ Evidence- \\
Based Medicine Epub ahead \\
of print: [please include Day \\
Month Year]. doi:10.1136/ \\
bmjebm-2020-111470 \\
\hline
\end{tabular}

\section{Abstract}

Concern has been raised about whether HPV vaccines might cause serious neurological disorders including postural orthostatic tachycardia syndrome (POTS) and chronic regional pain syndrome (CRPS). The European Medicines Agency (EMA) investigated the issue and declared in 2015 that there is no link between HPV vaccines and serious neurological adverse events. However, the certainty conveyed in EMA's official report is undermined by a leaked, confidential document that reveals important disagreements among the experts. Furthermore, in its assessments, EMA relied on the data the drug companies had provided to them even though it had been demonstrated that the companies had underreported possible neurological harms. Even though active comparators were used (aluminium adjuvants and other vaccines), our research group found significantly more serious neurological harms in the HPV vaccine groups than in the comparator groups in a systematic review based on clinical study reports in EMA's possession. We outline areas where we believe the basis for EMA's decision was flawed; highlight that the relationship between HPV vaccines and POTS remains uncertain; and suggest ways forward to resolve the uncertainty and debate.

Concern has been raised about whether HPV vaccines might cause serious neurological disorders including postural orthostatic tachycardia syndrome (POTS) and chronic regional pain syndrome (CRPS). ${ }^{1}$ Based on a request from Danish authorities, the European Medicines Agency (EMA) investigated the issue and published a 40-page report in November 2015 concluding that "the evidence does not support a causal association between HPV vaccination and CRPS and/or POTS. ${ }^{1}$

However, a leaked confidential report used to brief EMA's appointed scientific advisory group ${ }^{2}$ shows that there were important disagreements between the experts, suggesting more uncertainty in the science than the EMA report revealed..$^{134}$ In this analysis, we outline areas where we believe the scientific and procedural basis for EMA's decision was flawed; highlight that the relationship between HPV vaccine and POTS remains uncertain; and suggest ways forward to resolve the uncertainty and debate.

\section{Summary box}

- The European Medicines Agency (EMA) mishandled its investigation into concerns raised by Danish health authorities about suspected, serious neurological harms of HPV vaccines.

- Its official report was reassuring but a leaked, confidential EMA document reveals substantial disagreement among the agency's appointed experts.

- EMA trusted flawed data and analyses provided by the vaccine manufacturers and dismissed compelling evidence from independent researchers and the Uppsala Monitoring Centre.

- EMA sought advice from experts with financial conflicts of interests with vaccine manufacturers, failing to follow its own rules about conflicts of interest.

\section{Problems with the investigation}

HPV vaccines have been licenced across the USA and Europe since 2006, but within a few years, reports of suspected serious adverse events including POTS began to appear, ${ }^{5}$ with a majority reported from Denmark. ${ }^{1}$ In 2015, HPV vaccination rates declined in Denmark amidst media attention over serious adverse events. In July 2015, having received 363 serious adverse event reports, and aware of similar reports in Japan and elsewhere, the Danish Health and Medicines Authority asked the European Commission to initiate an in-depth review of the relationship between HPV vaccines and CRPS and POTS. ${ }^{1}$ The European Commission initiated an Article 20 pharmacovigilance procedure, and EMA assigned a rapporteur and two corapporteurs to the case and assembled a group of external advisors. ${ }^{1}$ Four months later, EMA released its official report, which concluded that the vaccines were safe.

However, there were several weaknesses in EMA's investigation and interpretation of the underpinning evidence, which cast doubts on its apparently certain conclusion. First, much of EMA's work consisted of requesting and reviewing investigations carried out by the manufacturers, and both they and EMA used several questionable 
methods. Second, EMA chose not to include important independent studies in its review while including other, less reliable data. We describe these weaknesses here.

\section{The review was not independent}

Rather than performing an independent assessment, EMA asked the companies to evaluate whether their vaccines are safe, specifically to review cases of CRPS and POTS in their trials, go through their postmarketing surveillance data, use these data to produce 'observed vs expected' analyses and review and assess the published scientific literature. $^{2}$

Not only does this raise questions about the independence of the process, but weaknesses in the scientific strategy employed by the companies is apparent. The official report ${ }^{1}$ did not mention that the search strategies the manufacturers used to search their databases were inadequate ${ }^{2}$ and will have led to many cases being overlooked. ${ }^{4}$ The companies did not search for headache, and 'dizziness' needed to occur together with 'orthostatic intolerance' or 'orthostatic heart rate response increased' in order to count. EMA nonetheless uncritically reproduced the incidence rates of CRPS and POTS c'onstructed by the manufacturers. ${ }^{4} 6$

Previous searches run by industry had also been inadequate. In 2014, the Danish drug regulator instructed Sanofi Pasteur MSD, which manufactured Gardasil, to search on specific symptoms in its database, including dizziness, palpitations, rapid heart rate, tremor, fatigue and fainting. Despite these instructions, Sanofi only searched on 'postural dizziness', 'orthostatic intolerance' and 'palpitations and dizziness'. The Danish authorities discovered this after only 3 of 26 reports of POTS that were registered in Denmark showed up in Sanofi's searches. ${ }^{7}$

Nevertheless, EMA trusted the drug companies. The text in the official report ${ }^{1}$ is nearly identical to the companies' own judgments about possible serious neurological harms. ${ }^{2}$

Making matters worse, Andrew Pollard, the chair of the EMA's Scientific Advisory Group, listed many relationships with vaccine manufacturers in his declaration to EMA. ${ }^{8}$ These included serving as a principal investigator for vaccine studies. While none were studies of HPV vaccines, some were of products made by GlaxoSmithKline, which manufacturers an HPV vaccine. In contrast, EMA restricted the participation of some advisors who did not have any financial or other interests. ${ }^{4}$ EMA says that it ensures those advising the agency do not have any financial or other interests that could affect the expert's impartiality, but given the facts of the situation with its investigation into POTS, this is debatable at best. $^{9}$

\section{Important independent studies were not included}

The original concerns that led the Danish regulator to ask EMA to conduct a review were based on a consecutive cohort of patients referred to the Danish Syncope Unit for a head-up tilt test due to orthostatic intolerance and symptoms compatible with autonomic dysfunction as a suspected adverse effect following HPV vaccination. ${ }^{10-12}$ However, in its public report, EMA accused the researchers of having presented 'a highly selected sample of patients, apparently chosen to fit a pre-specified hypothesis of vaccine-induced injury. ${ }^{1}$ This criticism was inappropriate, as Louise Brinth, the primary investigator, had explicitly stated that her findings were hypothesis generating only.

Furthermore, only 33 of the 83 cases of POTS that Brinth had described in a report, ${ }^{13} 41$ of which were from Denmark, were considered by the manufacturers-and therefore also by EMA-to have met the case definition. ${ }^{1}$ In our view, an assessment provided by a clinical expert who actually sees the patients is likely to be more reliable than a company employee looking at paperwork. Confidential EMA material ${ }^{14}$ shows that Danish authorities criticised EMA's exclusion of cases and also disagreed with EMA's assessment that 'the finding of the majority of POTS cases in Denmark does not support a causal relationship'. This disagreement between regulatory bodies was not mentioned in the confidential briefing note ${ }^{2}$ or in the official EMA report, which presented the conclusions as if based on unanimous agreement. ${ }^{1}$

In addition, EMA was unpersuaded by the data provided by the Uppsala Monitoring Centre, a WHO collaborating centre that accepts reports of suspected harms of vaccines and other drugs, even though the centre had found that POTS was reported 82 times more often for HPV vaccines than for other vaccines. ${ }^{2}$ EMA acknowledged the centre's finding that a substantially higher proportion of the cases related to HPV vaccine were serious but suggested the data were not compelling. Of the cases related to HPV vaccine, $80 \%$ with POTS and $78 \%$ with chronic fatigue syndrome (CFS) required admission to hospital or resulted in disability or interruption of normal function. ${ }^{12}$

Privately, key scientists at the Uppsala Monitoring Centre considered that their data were disregarded by EMA without adequate justification. ${ }^{4}$ Following EMA's report, they published a paper in 2016 reporting data that strengthened their suspicion that the HPV vaccines may cause serious harms. ${ }^{15}$ For the largest clusters they identified in the WHO VigiBase(R), the combination of headache and dizziness with either fatigue or syncope was more commonly reported in HPV vaccine reports than in non-HPV vaccine reports for females aged 9-25 years, and this disproportionality remained when those countries primarily reporting the signals of CRPS (Japan) and POTS (Denmark) were excluded. They also sought to reduce the possible influence of media attention by including only cases reported before 2015. Even so, they identified a greater number of potentially undiagnosed cases than the total number of cases labelled with one of these diagnoses by the drug companies.

\section{No placebo-controlled trials}

We also have concerns about the adequacy of the clinical trials used to support the approval of HPV vaccines to assess serious harms. On 15 May 2017, EMA Executive Director Guido Rasi explained to the EU Ombudsman that 'all studies submitted for the marketing authorisation application for Gardasil were placebo controlled: ${ }^{16}$ EMA's official report on POTS and CRPS also gives readers this impression and uses the term 'placebo cohorts' for the Gardasil trials. ${ }^{1}$

This is not true. None of the trials were truly placebo (ie, saline) controlled. In one trial, 597 children received a so-called 'placebo', which included all the excipients in the carrier solution. ${ }^{17}$ In another trial, of the nine-valent Gardasil 9, 306 participants received a saline placebo, but as they had all been vaccinated with the quadrivalent Gardasil earlier, ${ }^{18}$ those who did not tolerate the original HPV vaccine were likely not enrolled into the study. In the remaining trials, the control group received another vaccine, for example, against hepatitis A or $\mathrm{B},{ }^{24}$ which contain an adjuvant similar to that in the HPV vaccines. EMA did not address this fundamental problem in its official report. ${ }^{1}$

The use of active comparators may make it impossible to detect serious harms of the HPV vaccines in the randomised trials if the comparators cause the same or similar harms. This problem was criticised by two doctors external to EMA's expert group in the briefing note, ${ }^{2}$ but it was not mentioned in EMA's official report. ${ }^{1}$

Harms might potentially be caused by the aluminium adjuvants, which are used both in HPV vaccines and hepatitis vaccines. 
Rasi claimed in his letter to the Ombudsman that aluminium adjuvants in vaccines are safe. We checked the five references Rasi gave in support of his claim and found nothing to support it. ${ }^{15}$ We were unable to find any other evidence that the safety of the adjuvants has ever been tested in comparison with an inert substance in humans.

Even though active comparators were used, our research group found significantly more serious neurological harms in the HPV vaccine groups than in the comparator groups in a systematic review that was based on clinical study reports in EMA's possession. ${ }^{17}$ Our research was accepted for publication in Systematic Reviews, a journal owned by Springer, on 6 March 2019. However, a year later, it had still not been published although the journal promises publication within 20 days of acceptance. We had been given a total of 20 apologies and a variety of odd, contradictory and implausible reasons why our paper had not been published. To us, this looked like scientific censorship, and our review was not published before we announced that we would take legal action and gave Springer a deadline of 1 March 2020. ${ }^{19}$ It was published the day before the deadline.

The 2018 Cochrane review of the HPV vaccines did not find such harms, but it was based on published trial reports only ${ }^{20}$ and overlooked important harms. ${ }^{21}$

The changes in the immune system elicited by strongly immunogenic vaccines or adjuvants might render the vaccinated women more susceptible to the development of POTS or CRPS after an otherwise harmless viral illness. EMA stated in a report based on its own literature searches that 'POTS ... frequently start after viral illness.,22

EMA did not convey this possibility in its briefing note to its experts, which referred to its literature searches but also had a statement that 'Confidential information was removed.' However, there was nothing confidential in them, and Rasi stated in his letter to the Ombudsman that 'said icon was inadvertently deleted further to a clerical error. ${ }^{15}$ We got access to the missing results from the literature searches after the Ombudsman had encouraged us to obtain them from EMA.

\section{The experts disagreed on the interpretation of the data}

A key EMA argument, mentioned multiple times in its official report, ${ }^{1}$ was that there was no difference between what was observed in vaccinated girls and the expected background incidence of POTS and CRPS. However, the quality of the underlying data was too poor to draw such conclusions. In some analyses, the observed incidence of chronic fatigue syndrome was used to estimate the expected incidence of POTS, which likely led to an overestimate of the expected incidence and thus a reduced chance to detect a harms signal. ${ }^{2}$ Furthermore, EMA noted that for POTS, the observed number of cases was generally lower than expected under almost all assumptions except for Denmark, ${ }^{1}$ an observation that should have raised serious concerns about the reliability of such analyses.

The briefing note revealed that the Belgian and Swedish corapporteurs were critical of the observed versus expected analyses. ${ }^{2}$ Yet while EMA did acknowledge limitations in the data underlying these analyses in its report, these concerns did not seem to affect the certainty of conclusions conveyed in their summary statements. ${ }^{1}$

Nowhere in the public report are the dissenting views of EMA's appointed corapporteurs recorded. According to the leaked briefing note, the Belgian corapporteur recommended 'further evaluation of CRPS and POTS' in relation to Cervarix, one of the two HPV vaccines. ${ }^{2}$ However, this critical fact, too, was not included in the public report. ${ }^{1}$

\section{Conclusions}

Public trust in drug regulation, including for vaccines, relies on transparency, honesty about uncertainties and adequate, unconflicted assessment of benefits and harms. EMA's practice of leaving investigations of suspected serious harms to the manufacturers does not further public trust and should be revised.

As is the general rule for other drugs, placebo or no-treatment controls are needed in trials of vaccines in order to study the occurrence of harms before drug approval. If considered unethical for the HPV vaccines, dose-response studies could be carried out. When Merck compared its nine-valent Gardasil 9 with quadrivalent Gardasil in 14215 women, there were more serious systemic adverse events in the Gardasil 9 group (3.3\% vs 2.6\%, $p=0.01$, our calculation). ${ }^{22}$ Gardasil 9 has four more antigens than the quadrivalent vaccine and contains $500 \mu \mathrm{g}$ of the aluminium adjuvant, compared with only $225 \mu \mathrm{g}$. The safety of the aluminium adjuvants commonly used in vaccines should be tested.

EMA should avoid using experts in its committees with conflicts of interest and should make available all reports on its website, including those used for deliberations in its scientific advisory groups.

Correction notice This article has been corrected since it appeared Online First. Affiliation for Karsten Juhl Jørgensen has been corrected to "Nordic Cochrane Centre, Copenhagen, Denmark".

Acknowledgements We would like to thank the coauthors on our complaints to the European Medicines Agency and the European Ombudsman: Dr Tom Jefferson, MEP Margrete Auken and Dr Louise Brinth.

Contributors PCG wrote the first and subsequent drafts, and KJJ contributed.

Funding The authors have not declared a specific grant for this research from any funding agency in the public, commercial or not-for-profit sectors.

\section{Competing interests None declared.}

Patient consent for publication Not required.

Provenance and peer review Not commissioned; externally peer reviewed.

Open access This is an open access article distributed in accordance with the Creative Commons Attribution Non Commercial (CC BY-NC 4.0) license, which permits others to distribute, remix, adapt, build upon this work non-commercially, and license their derivative works on different terms, provided the original work is properly cited, appropriate credit is given, any changes made indicated, and the use is non-commercial. See: http://creativecommons.org/licenses/by-nc/4.0/.

\section{ORCID iD}

Peter C Gøtzsche http://orcid.org/0000-0002-2108-7016

\section{References}

1 European Medicines Agency. Assessment report. review under article 20 of regulation (EC) NO 726/2004. human papilloma virus (HPV) vaccines, 2015. Available: http://www.ema.europa.eu/docs/en_GB/document_library/ Referrals_document/HPV_vaccines_20/Opinion_provided_by_Committee_ for_Medicinal_Products_for_Human_Use/WC500197129.pdf 
2 Briefing note to experts. EMA/666938/2015, 2015. Available: http://ijme. in/pdf/g-briefing-note-to-the-experts-ema-oct-2015-unredacted.pdf

3 Gøtzsche PC, Jørgensen KJ, Jefferson T. Complaint to the European medicines Agency (EMA) over maladministration at the EMA, 2016. Available: http://www.deadlymedicines.dk/wp-content/uploads/2019/02/ 10.-2016-05-26-Complaint-to-EMA-over-EMAs-handling-of-safety-of-theHPV-vaccines.pdf

4 Gøtzsche PC, Jørgensen KJ, Jefferson T. Complaint to the European Ombudsman over maladministration at the European Medicines Agency (EMA) in relation to the safety of the HPV vaccines, 2016. Available: http://www.deadlymedicines.dk/wp-content/uploads/2019/02/8.-2016-1010-Complaint-to-the-EU-ombudsman-over-the-EMA.pdf

5 Jørgensen L, Doshi P, Gøtzsche P, et al. Challenges of independent assessment of potential harms of HPV vaccines. BMJ 2018;362:k3694.

6 Jefferson T, Jørgensen L. Human papillomavirus vaccines, complex regional pain syndrome, postural orthostatic tachycardia syndrome, and autonomic dysfunction - a review of the regulatory evidence from the European Medicines Agency. Indian J Med Ethics 2017;2:30-7.

7 Weber C, Andersen S. Firma bag HPV-vaccinen underdrev omfanget af alvorlige bivirkninger. Berlingske 26. oktober, 2015.

8 Pollard A. Public Declaration of interests and confidentiality undertaking of European Medicines Agency (EMA), scientific committee members and experts. Public Declaration of interests https://exploredoc.com/doc/ 2853343/i-andrew-pollard-european-medicines-agency

9 Letter from the EMA to the Nordic Cochrane Centre, 2016. Available: http://www.ema.europa.eu/docs/en_GB/document_library/Other/2016/07/ WC500210543.pdf

10 Brinth L, Theibel AC, Pors K, et al. Suspected side effects to the quadrivalent human papilloma vaccine. Dan Med J 2015;62:A5064.

11 Brinth LS, Pors K, Theibel AC, et al. Orthostatic intolerance and postural tachycardia syndrome as suspected adverse effects of vaccination against human papilloma virus. Vaccine 2015;33:2602-5.

12 Brinth L, Pors K, Hoppe AAG, et al. Is chronic fatigue syndrome/myalgic encephalomyelitis a relevant diagnosis in patients with suspected side effects to human papilloma virus vaccine? Int J Vaccines Vaccin 2015;1:00003.
13 Brinth L. Responsum to assessment report on HPV-vaccines released by EMA November 26th 2015, 2015. Available: http://www.ft.dk/samling/ 20151/almdel/suu/bilag/109/1581470.pdf

14 PRAC co-rapporteur's referral updated assessment report. Updated report, 2015. Available: http://www.deadlymedicines.dk/wp-content/uploads/2019/ 06/PRAC-co-rapporteur\%E2\%80\%99s-referral-updated-assessment-report28-0ct-2015.pdf

15 Chandler RE, Juhlin K, Fransson J, et al. Current safety concerns with human papillomavirus vaccine: a cluster analysis of reports in VigiBase ${ }^{\circledR}$ Drug Saf 2017;40:81-90.

16 Gøtzsche PC, Jørgensen KJ, Jefferson T. Our Comment on the decision by the European Ombudsman about our complaint over maladministration at the European Medicines Agency related to safety of the HPV vaccines, 2017. Available: http://www.deadlymedicines.dk/wp-content/uploads/ 2019/02/1.-2017-11-02-Our-assessment-on-the-Ombudsmans-decision. pdf

17 Jørgensen L, Gøtzsche PC, Jefferson T. Benefits and harms of the human papillomavirus (HPV) vaccines: systematic review with meta-analyses of trial data from clinical study reports. Syst Rev 2020;9:43.

18 A study of V503, a 9-valent human papillomavirus (9vHPV) vaccine in females 12-26 years of age who have previously received GARDASIL ${ }^{\mathrm{TM}}$ (V503-006). Available: https://clinicaltrials.gov/show/NCT01047345

19 Arbyn M, Xu L, Simoens C, et al. Prophylactic vaccination against human papillomaviruses to prevent cervical cancer and its precursors. Cochrane Database Syst Rev 2018;5:CD009069.

20 Jørgensen L, Gøtzsche PC, Jefferson T. The Cochrane HPV vaccine review was incomplete and ignored important evidence of bias: response to the Cochrane editors, 2018. Available: https://ebm.bmj.com/content/early/ 2018/07/27/bmjebm-2018-111012.responses\#the-cochrane-hpvvaccinereview-was-incomplete-and-ignored-important-evidence-of-bias-responseto-the-cochraneeditors

21 Benarroch EE. Postural tachycardia syndrome: a heterogeneous and multifactorial disorder. Mayo Clin Proc 2012;87:1214-25.

22 Joura EA, Giuliano AR, Iversen OE, et al. A 9-valent HPV vaccine against infection and intraepithelial neoplasia in women. $N$ Engl J Med 2015;372:711-23. 